\title{
Differences in Risk Factors for Suicidal Ideation among Younger, Middle-Aged, and Older Adults
}

\author{
Saeheon Jang, MD \\ Department of Psychiatry, Bong Seng Memorial Hospital, Busan, Korea
}

Background: Life stressors and habits that influence suicidal ideation (SI) differ across the life cycle. The study aims to analyze the different risk factors for SI among younger, middle-aged, and older adults.

Methods: The current study used data from the 4th (2007-2009) to the 6th (2013-2015) Korea National Health and Nutrition Examination Survey (KNHANES). The researchers recruited a total of 49,487 adults over 19 years of age with no missing values in marital status, household income, area of residence, employment status, level of education, and regular walking.

Results: The results identified depression, sex, alcohol problem, education, smoking, marital status, household income, and social care as risk factors for SI in the total sample. In younger adults, regular PA was included as a risk factor for SI, whereas social care was excluded from the risk factors. In middle-aged adults, educational attainment and social care were excluded from the risk factors for SI. In older adults, marital and job statuses were excluded from the risk factors for SI.

Conclusion: Several common risk factors for SI have been identified in adults over 19 years of age. According to their stage in the life cycle, there were several differences in the risk factors for SI.

Keywords Suicidal ideation; Risk factors; Age

\section{INTRODUCTION}

Suicide is one of the major public health issues worldwide. There were an estimated 793,000 suicide deaths worldwide in 2016. This indicates an annual global agestandardized suicide rate of 10.5 per 100,000 population and makes suicide the 10th leading cause of death worldwide [1,2].

Suicide phenomenon can be defined as a continuum of suicidal ideation (SI), suicide attempt, and complete suicide [3]. SI is the first warning sign of an impending suicide attempt or suicide and an important process that leads to next step of suicide phenomenon. The average twelve-month prevalence estimates are $2.0 \%$ and $2.1 \%$ for SI, and $0.3 \%$ and $0.4 \%$ for suicide attempts in de- veloped and developing countries, respectively [4]. The majority of those who commit suicide succeed in their first attempt. As there is a strong relationship between SI and attempted and completed suicide, identifying risk factors and treatments for people experiencing SI is essential to reduce suicide attempts and deaths.

Risk factors for SI include psychiatric and sociodemographic factors. Psychiatric factors include major depression, bipolar affective disorders, schizophrenia, and alcohol use disorders [5]. Socio-demographic factors include female sex, young age, low educational level, low income, single relationship status, and lack of economic activity $[4,6]$.

Meanwhile, people have different developmental tasks that need to be completed over the life span. Life stress-

Received March 8, 2021, Revised April 24, 2021, Accepted May 27, 2021

Correspondence: Saeheon Jang, MD

Department of Psychiatry, Bong Seng Memorial Hospital, 401, Joongang-daero, Dong-gu, Busan 48775, Korea

TEL +82-51-664-4120 FAX +82-51-631-8054 E-mail powernp@nate.com ORCID https://orcid.org/0000-0002-4186-1101

Copyright $@$ by Korean Society for Affective Disorders.

This is an Open Access article distributed under the terms of the Creative Commons Attribution Non-Commercial License (http://creativecommons.org/licenses/ by-nc/4.0/) which permits unrestricted non-commercial use, distribution, and reproduction in any medium, provided the original work is properly cited. 
ors and factors influencing SI will differ across the life cycle. Young adults are less likely to commit suicide if they have a professional occupation. For the middle aged, SI is less likely when they have good friendships, active hobbies, physical activity (PA), and social support [7]. Older people are less likely to commit suicide when they are religious and emotionally stable [8-10].

If specific risk factors for age-related SI can be identified, age-specific preventive measures can be applied. We wanted to see if there is a difference across the age groups in risk factors for SI.

\section{MATERIALS AND METHODS}

This study used data from the 4th (2007-2009) to the 6th (2013-2015) Korea National Health and Nutrition Examination Survey (KNHANES) conducted by the Korea Centers for Disease Control and Prevention (KCDC). The KNHANES has been conducted periodically to assess the health and nutritional status of the noninstitutionalized Korean civilian population and held annually from the beginning of 4th (2007-2009) survey. The KNHANES is composed of a health interview survey module, a health examination survey module and a nutrition survey module conducted by trained interviewers.

Age, sex, region (urban vs. rural area), marital status (single vs. married), household income (low, mid-low, mid-high, high), education level (elementary, middle, high, college), employment status, and social care were used as indicators of socioeconomic status. Health behaviors such as smoking, drinking (Alcohol Use Disorder Identification Test [AUDIT]; low: scores of 0-12, doubtful: scores 13-19, high: scores 20 and more), and PA (walking regularly: walking for 30 minutes or more once a week up to walking for 30 minutes or more for 5 days or more during the last week) were assessed through self-reported questionnaires. Depression was defined as participants answering 'yes' to a question of whether they had experienced a depressed mood for 2 or more continuous weeks during the previous year. SI was assessed by a positive answer to the question "In the last 12 months, did you think about committing suicide?" If they answered 'yes', they were asked about their suicide attempts, if any. The age groups were analyzed by dividing the population into young adults (19-39 years old), middle-aged (40-59 years old), and older adults (60 years old or older).

A total of 49,487 adults over the age of 19 who had no missing values in marital status, household income, areas of residence, employment status, level of education, and regular PA were selected for the study.

Discrete variables such as sex and disease status, were evaluated using the chi-square test. The association between SI and study variables was assessed by univariate analysis and multiple logistic regression analysis. Statistical significance of this study was defined as p-value $<0.05$ in both directions, and all statistical analyzes were performed using IBM SPSS 23.0 (IBM Corp., Armonk, NY, USA).

This study was conducted after obtaining the approval of the Institutional Review Board of Bong Seng Memorial Hospital in Busan, Korea (approval number: BSIRB-2020-003). As this study used publicly available data, informed consent was exempted.

\section{RESULTS}

\section{Demographic characteristics}

Table 1 shows the results of frequency analysis on the general characteristics of the subjects for each major demographic variable. There were 21,407 male (43.3\%) and 28,028 female (56.7\%). There were 15,091 people (30.5\%) in the young adults group, 18,484 people (37.4\%) in the middle-aged group, and 15,912 people $(32.2 \%)$ in the older adults group. The frequency of married people was highest in older adults (99.5\%) and lowest in young adults (59.3\%). The frequency of low-income group was highest in older adults (44.4\%), and lowest in young adults (7.6\%). The frequency of high income was highest for the middle-aged (36.0\%), and lowest for older adults $(12.4 \%)$. The highest reported category of education level for young adults was college graduate $(52.9 \%)$, for the middle aged was high school graduate (39.2\%), and for older adults was elementary school graduate (63.3\%). The employment status of being employed was highest for the middle-aged (72.2\%) and lowest for older adults $(38.8 \%)$. The frequency of city residency was highest in young adults $(86.2 \%)$, and lowest in older adults $(66.8 \%)$. 
Table 1. Demographic data in each age group

\begin{tabular}{|c|c|c|c|c|c|}
\hline Factor & $\begin{array}{c}\text { Total } \\
(n=49,487)\end{array}$ & $\begin{array}{l}\text { Young adults } \\
(n=15,091)\end{array}$ & $\begin{array}{c}\text { Middle aged } \\
(n=18,484)\end{array}$ & $\begin{array}{l}\text { Old adults } \\
(n=15,912)\end{array}$ & $\mathrm{p}$-value \\
\hline Age (y) & 50.3 & 31.0 & 49.3 & 69.7 & ** \\
\hline Sex, male & 43.3 & 42.9 & 43.9 & 42.8 & ns \\
\hline Marital status, married & 86.5 & 59.3 & 97.2 & 99.5 & ** \\
\hline Household income $^{a}$ & & & & & ** \\
\hline Low & 20.4 & 7.6 & 10.5 & 44.4 & \\
\hline Mid-low & 25.5 & 25.6 & 24.1 & 27.1 & \\
\hline Mid-high & 26.7 & 34.4 & 29.5 & 16.0 & \\
\hline High & 27.4 & 32.5 & 36.0 & 12.4 & \\
\hline Social care, $(+)$ & 6.8 & 4.7 & 5.6 & 10.3 & $\star \star$ \\
\hline Educational level & & & & & ** \\
\hline$\leq$ Elementary & 26.9 & 0.6 & 16.7 & 63.3 & \\
\hline Middle & 11.0 & 2.0 & 16.1 & 13.6 & \\
\hline High & 33.2 & 44.6 & 39.2 & 15.5 & \\
\hline$\geq$ College & 28.9 & 52.9 & 28.0 & 7.7 & \\
\hline Employment state, yes & 58.5 & 62.6 & 72.2 & 38.8 & $\star \star$ \\
\hline Area of residence, city & 77.3 & 86.2 & 79.1 & 66.8 & ** \\
\hline Regular walking, $(+)^{\mathrm{b}}$ & 82.8 & 80.1 & 84.7 & 83.4 & ** \\
\hline Depression, (+) & 6.8 & 4.7 & 5.6 & 10.3 & ** \\
\hline Alcohol problem risk ${ }^{\mathrm{C}}$ & & & & & ** \\
\hline Low & 85.1 & 82.6 & 81.8 & 91.0 & \\
\hline Doubtful & 10.1 & 12.0 & 11.9 & 6.3 & \\
\hline High & 4.9 & 5.4 & 6.3 & 2.7 & \\
\hline Smoking-present & & & & & $\star \star$ \\
\hline$(+)$ & 79.5 & 73.5 & 78.5 & 86.3 & \\
\hline$(-)$ & 20.5 & 26.4 & 21.5 & 13.7 & \\
\hline Suicidal ideation, (+) & 13.9 & 11.0 & 12.0 & 19.0 & $\star \star$ \\
\hline
\end{tabular}

Values are presented as percentage only.

ns, non-significance.

'Low: less than 2 million won per year, mid-low: between 2 and 80 million won per year, mid-high: between 80 and 180 million won per year, high: over 180 million won per year.

${ }^{b}$ Walking for 30 minutes or more once a week for 5 days or more during the last week.

'Low: Alcohol Use Disorder Identification Test (AUDIT) scores of 0-12, doubtful: AUDIT scores 13-19, high: AUDIT scores 20 and more. $\star p<0.05, * * p<0.01$.

\section{Health behavior (drinking alcohol, regular walking), depression, and suicidal ideation by age}

The frequency of people walking regularly was highest for the middle aged $(84.7 \%)$, and lowest for young adults $(80.1 \%)$. The frequency of people with high alcohol consumption was highest for the middle aged (6.3\%), and lowest for older adults (2.7\%).

The frequency of people experiencing a depressed mood for 2 or more continuous weeks during the previous year was highest in older adults (10.3\%) and lowest in young adults $(4.7 \%)$. The frequency of people with SI was highest in older adults (19.0\%) and lowest in young adults $(11.0 \%)$.

\section{Univariate analysis of relating factors for suicidal ideation by age}

Most of the variables considered such as sex, area of residency, marital status, household income, social care, educational level, employment status, regular walking, alcohol problem risk, depression, except for smokingpresent, showed significance with SI in the total sample. 
Table 2. Univariate analysis of relating factors for $\mathrm{SI}$ in each age group

\begin{tabular}{|c|c|c|c|c|c|c|c|c|c|}
\hline \multirow{2}{*}{ Group } & & \multicolumn{2}{|c|}{ Total } & \multicolumn{2}{|c|}{ Young adults } & \multicolumn{2}{|c|}{ Middle aged } & \multicolumn{2}{|c|}{ Old adults } \\
\hline & & $\%$ of SI & $\mathrm{p}$-value & $\%$ of $\mathrm{SI}$ & $p$-value & \% of SI & $p$-value & \% of SI & $p$-value \\
\hline \multirow[t]{2}{*}{ Sex } & Male & 9.3 & $\star \star$ & 6.6 & ** & 9.0 & $\star \star$ & 12.7 & $\star \star$ \\
\hline & Female & 17.1 & & 14.1 & & 14.2 & & 23.6 & \\
\hline \multirow[t]{2}{*}{ Area of residency } & Urban & 13.0 & $\star \star$ & 13.7 & ns & 11.8 & ns & 17.2 & $\star \star$ \\
\hline & Rural & 16.3 & & 12.8 & & 12.9 & & 22.3 & \\
\hline \multirow[t]{2}{*}{ Marital status } & Married & 12.3 & $\star \star$ & 10.3 & $\star \star$ & 11.9 & $\star \star$ & 18.9 & $\star \star$ \\
\hline & Single & 14.2 & & 11.9 & & 16.5 & & 25.8 & \\
\hline \multirow[t]{4}{*}{ Household income ${ }^{a}$} & Low & 22.2 & $\star \star$ & 16.5 & ** & 21.8 & $\star \star$ & 24.3 & ** \\
\hline & Mid-low & 14.4 & & 12.4 & & 15.1 & & 16.7 & \\
\hline & Mid-high & 11.3 & & 10.6 & & 11.1 & & 12.6 & \\
\hline & High & 9.3 & & 8.8 & & 7.8 & & 11.3 & \\
\hline \multirow[t]{2}{*}{ Social care } & $(+)$ & 24.9 & $\star \star$ & 16.3 & $\star \star$ & 25.8 & ** & 30.9 & $\star \star$ \\
\hline & $(-)$ & 12.9 & & 10.7 & & 11.2 & & 17.6 & \\
\hline \multirow[t]{4}{*}{ Educational level } & $\leq$ Elementary & 21.0 & ** & 25.3 & ** & 20.8 & ** & 24.0 & ** \\
\hline & Middle & 13.7 & & 22.6 & & 14.7 & & 12.6 & \\
\hline & High & 11.4 & & 12.8 & & 10.1 & & 9.7 & \\
\hline & $\geq$ College & 8.3 & & 8.9 & & 7.5 & & 7.7 & \\
\hline \multirow[t]{2}{*}{ Employment status } & Employed & 11.3 & $\star \star$ & 9.7 & $\star \star$ & 10.5 & ** & 15.3 & ** \\
\hline & Unemployed & 17.0 & & 13.4 & & 16.0 & & 21.3 & \\
\hline \multirow[t]{2}{*}{ Regular walking ${ }^{b}$} & $(-)$ & 13.0 & * & 9.9 & * & 12.9 & * & 22.4 & ** \\
\hline & $(+)$ & 13.9 & & 11.2 & & 11.4 & & 16.7 & \\
\hline \multirow[t]{2}{*}{ Smoking-present } & $(-)$ & 13.9 & ns & 10.9 & ns & 11.5 & ns & 18.7 & ns \\
\hline & $(+)$ & 14.1 & & 11.2 & & 13.6 & & 20.2 & \\
\hline \multirow[t]{3}{*}{ Alcohol problem risk ${ }^{c}$} & Low & 13.6 & $\star \star$ & 10.5 & $\star \star$ & 11.5 & $\star \star$ & 19.2 & $\star \star$ \\
\hline & Doubt & 11.7 & & 10.2 & & 12.0 & & 13.5 & \\
\hline & High & 19.7 & & 19.8 & & 19.0 & & 21.4 & \\
\hline \multirow[t]{2}{*}{ Depression } & $(+)$ & 48.8 & $\star \star$ & 44.6 & $\star \star$ & 45.5 & $\star \star$ & 54.4 & $\star \star$ \\
\hline & $(-)$ & 8.2 & & 6.6 & & 6.6 & & 11.6 & \\
\hline
\end{tabular}

SI, suicidal ideation; ns, non-significance.

aLow: less than 2 million won per year, mid-low: between 2 and 80 million won per year, mid-high: between 80 and 180 million won per year, high: over 180 million won per year.

${ }^{b}$ Walking for 30 minutes or more once a week for 5 days or more during the last week.

'Low: Alcohol Use Disorder Identification Test (AUDIT) scores of $0-12$, doubtful: AUDIT scores 13-19, high: AUDIT scores 20 and more. $\star p<0.05, * \star p<0.01$.

This result was similar in the subgroup univariate analysis by age except the area of residence which was related to suicide ideation in the elderly, but not in young adults and middle-aged (Table 2).

\section{Multiple logistic regression analysis of relating factors for suicidal ideation in each age group}

Depression (odds ratio [OR], 9.35; 95\% confidence interval [CI], 8.70-10.04) showed the highest OR associated with suicide ideation in total and in age sub-groups also. Next, the high alcohol problem risk (OR, 1.94; $95 \%$ CI, 1.67-2.24) showed high OR, followed by elementary school graduation (OR, 1.93; 95\% CI, 1.73-2.15), female (OR, 1.81; 95\% CI, 1.67-1.99), and low household income (OR, 1.62; 95\% CI, 1.44-1.81) in total sample. The smoking-present, area of residency, and regular walking was not associated with suicide ideation in the total sample.

These results showed some differences in age-subgroup analysis. In detail, the area of residency and regular walking showed some significance with SI in older adults unlike in other age groups. The marital status did not show significance with SI in middle-aged and older 


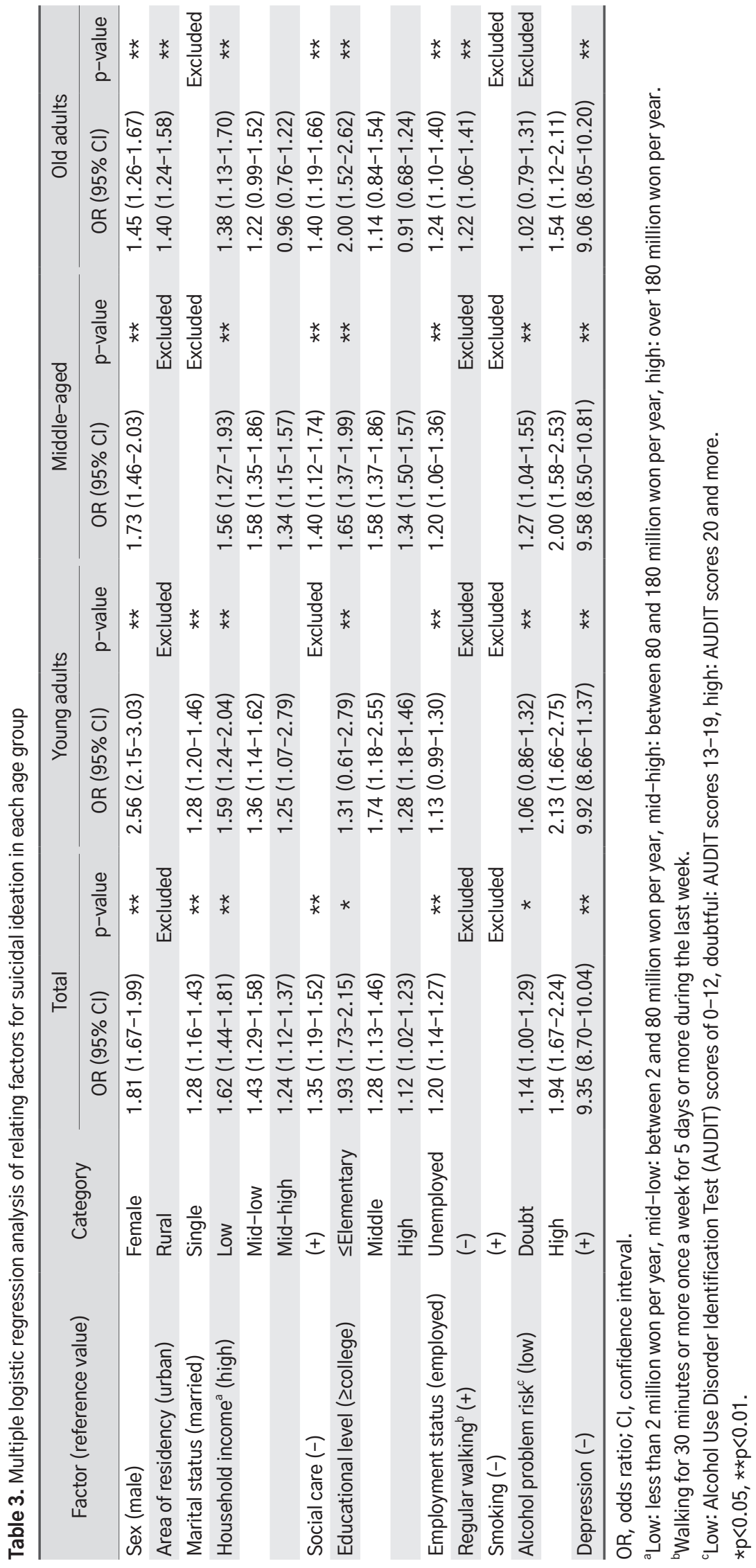


adults, social care did not show significance with SI in young adults, alcohol problem risk did not show significance with SI in older adults (Table 3 ).

\section{DISCUSSION}

In this study, we examined various demographic, health behaviors, and psychiatric variables related to SI and examined their differences through life cycle. As expected, depression was the most important factor associated with suicidal thoughts at all ages. Recurrent thought of death or recurrent SI is the 8th item of Depression DSM-5 Diagnostic Criteria. The prevalence of SI was high among adults with major depression, and if it is accompanied by substance abuse, the prevalence increases further [11].

Interestingly, depression alone is poor predictor of subsequent suicidal behavior. That is because lethargy in depression may serve as a protective factor against suicide attempts. Conversely, heightened arousal may serve as a suicide risk factor [12]. This is something to keep in mind when predicting suicide risk in depressed patients who have had a SI.

Alcohol use has consistently been implicated in the precipitation of suicidal behavior. Alcohol abuse may lead to suicidality through disinhibition, impulsiveness, and impaired judgment [13]. However, it may also be used to ease the distress associated with committing an act of suicide. In this study, high alcohol problem was associated with SI according to conventional wisdom. However, our result that moderate alcohol use (doubtful alcohol problem) was found to have a lower risk of suicide than low alcohol use especially in older adults (Table 2) can be explained by the stress-relieving function of alcohol. However, these results cannot justify alcohol use. This is because continuous drinking can eventually lead to alcohol use disorder. The reason why the risk of suicide was lower in moderate drinking in the elderly may be attributed to the fact that alcohol in the elderly group does not lead to excessive drinking due to physical weakness which causes alcohol intolerance.

Socioeconomic state such as lower educational levels, female gender, unmarried or live alone [14], and low income traditionally considered as a high-risk factor for SI. In our study, lower education, female gender, and poor economic state (low household income or poorness or employment state) were confirmed as risk factors for
SI at all ages. But unmarried or living alone was considered as a significant risk factor for suicide ideation only in young adults, unlike other ages. Young married adults (especially those who first married at age 22-26) report higher life satisfaction than those in other types of relationships or no relationship at all [15]. However, another study of young adults found mixed effects of marriage on mental health that varied across outcomes and by race and gender [16]. Still, the relationships between marriage and cohabitation with mental health during the transition to adulthood are not well understood. Living alone and marital status may have an influence on depression in middle-aged and older adults [17]. However, in this study we did not analyze the association of suicide ideation with marital status by subdividing it into cohabitation, separation, divorce, and bereavement. So, we cannot confirm the influence of marital status on SI for middle-aged and older adults. The relationship between marital status and SI still seems to be difficult to clarify.

There is strong evidence that PA has been shown to reduce several important risk factors for suicide including depressive symptoms, anxiety symptoms, symptoms of psychosis, disturbed sleep, alcohol abuse, and chronic somatic conditions. Those who were "active" versus those who were "inactive" were less likely to have SI [18]. Physical inactivity may contribute to anxiety and depression [19]. People with established depression are known to engage in low levels of moderate-vigorous PA and are less likely to meet recommended PA guidelines. There has been growing interest in the potential relationship between sedentary behavior (SB) and depression. SB refers to any waking behavior characterized by an energy expenditure $\leq 1.5$ metabolic equivalents, while in a sitting, reclining, or lying posture [20]. Furthermore, engaging in structured PA ("exercise") has been demonstrated to be an effective treatment for depression [21]. However, there are some variations in associations between PA in various domains (leisure, work, active commuting, yard/household chores) and depression [22]. Relatively low durations of leisure PA $(\leq 1.25$ hours/ week) were associated with lower prevalence of depression. In contrast, high durations of work PA were associated with higher prevalence of depression compared with being sedentary. Many other studies have reported associations between SI and physical inactivity in the elderly [23] and adolescents [24]. In this study, physical inactivity was found to have a greater impact on the 
risk of SI in young adults than in other age groups. So, it can be said that physically inactive situations can have a greater negative impact on mental health in a young physically active age.

However, this study has some limitations. First, this study was not a well-designed targeted study. Instead, it was based on cross-sectional survey data that showed the relationship between suicide ideation and various sociodemographic and health related variables and was not able to reveal a causal relationship. Second, as it is difficult to obtain data on suicide, which is the final result of SI, an in-depth analysis on suicidal behavior was not available. Since PA was not classified into leisure activities, commuting, labor, and SB, a more detailed analysis was not conducted.

However, this study has some significant advantages. This study was conducted based on a large sample by integrating nation-wide health and nutrition data conducted over several years. And it is important to analyze the risk factors affecting suicide accidents by age in adults. In particular, in a situation where physical inactivity increases due to the COVID-19 pandemic situation, the result that physical inactivity may increase the risk of suicidal accidents in young people with active PA can be said to have many implications.

\section{CONCLUSION}

Several common risk factors for SI have been identified in adults over 19 years of age. According to the life cycle, there were some differences in risk factors for SI. Based on these results, it may be necessary to apply differential suicide prevention measures according to life cycle.

\section{CONFLICTS OF INTEREST}

The authors have nothing to disclose.

\section{ORCID}

\author{
Saeheon Jang \\ https://orcid.org/0000-0002-4186-1101
}

\section{REFERENCES}

1. Turecki G, Brent DA. Suicide and suicidal behaviour. Lancet 2016;387:1227-39.

2. World Health Organization. Preventing suicide: a resource for primary health care workers. Geneva: World Health Organization; 2000.

3. Sveticic J, De Leo D. The hypothesis of a continuum in suicidality: a discussion on its validity and practical implications. Ment Illn 2012;4:e15.

4. Borges G, Nock MK, Haro Abad JM, Hwang I, Sampson NA, Alonso J, et al. Twelve-month prevalence of and risk factors for suicide attempts in the World Health Organization World Mental Health Surveys. J Clin Psychiatry 2010; 71:1617-28.

5. Suominen K, Isometsä E, Suokas J, Haukka J, Achte K, Lönnqvist J. Completed suicide after a suicide attempt: a 37-year follow-up study. Am J Psychiatry 2004;161:562-3.

6. Forkmann T, Brähler E, Gauggel S, Glaesmer H. Prevalence of suicidal ideation and related risk factors in the German general population. J Nerv Ment Dis 2012;200:401-5.

7. Jo A, Jeon M, Oh H. Age-differentiated risk factors of suicidal ideation among young and middle-aged Korean adults. Osong Public Health Res Perspect 2017;8:201-10.

8. Stack S, Lester D. The effect of religion on suicide ideation. Soc Psychiatry Psychiatr Epidemiol 1991;26:168-70.

9. Ra CK, Cho Y. Differentiated effects of social participation components on suicidal ideation across age groups in South Korea. BMC Public Health 2013;13:890.

10. Kim SY, Jung MY, Kim KN. Factors associated with suicidal ideation by age group among Korean adults: using the fifth Korea National Health and Nutrition Examination Survey (KNHANES V, 2012). Korean J Health Educ Promot 2014;31:1-14

11. Han B, McKeon R, Gfroerer J. Suicidal ideation among community-dwelling adults in the United States. Am J Public Health 2014;104:488-97.

12. Rogers ML, Ringer FB, Joiner TE. The association between suicidal ideation and lifetime suicide attempts is strongest at low levels of depression. Psychiatry Res 2018;270:324-8.

13. Pompili M, Serafini G, Innamorati M, Dominici G, Ferracuti S, Kotzalidis GD, et al. Suicidal behavior and alcohol abuse. Int J Environ Res Public Health 2010;7:1392-431.

14. Choi YJ, Lee WY. The prevalence of suicidal ideation and depression among primary care patients and current management in South Korea. Int J Ment Health Syst 2017;11: 18.

15. Uecker JE. Marriage and mental health among young adults. J Health Soc Behav 2012;53:67-83.

16. Harris KM, Lee H, Deleone FY. Marriage and health in the transition to adulthood: evidence for African Americans in add health. J Fam Issues 2010;31:1106-43.

17. Dean A, Kolody B, Wood P, Matt GE. The influence of living alone on depression in elderly persons. J Aging Health 
1992;4:3-18.

18. Vancampfort D, Hallgren M, Firth J, Rosenbaum S, Schuch FB, Mugisha J, et al. Physical activity and suicidal ideation: a systematic review and meta-analysis. J Affect Disord 2018;225:438-48.

19. Silva LRB, Seguro CS, de Oliveira CGA, Santos POS, de Oliveira JCM, de Souza Filho LFM, et al. Physical inactivity is associated with increased levels of anxiety, depression, and stress in Brazilians during the COVID-19 pandemic: a cross-sectional study. Front Psychiatry 2020;11:565291.

20. Tremblay MS, Aubert S, Barnes JD, Saunders TJ, Carson V, Latimer-Cheung AE, et al. Sedentary Behavior Research Network (SBRN) - Terminology Consensus Project process and outcome. Int J Behav Nutr Phys Act 2017;14:75.

21. Schuch FB, Vancampfort D, Richards J, Rosenbaum S, Ward PB, Stubbs B. Exercise as a treatment for depression: a meta-analysis adjusting for publication bias. J Psychiatr Res 2016;77:42-51.

22. McKercher CM, Schmidt MD, Sanderson KA, Patton GC, Dwyer T, Venn AJ. Physical activity and depression in young adults. Am J Prev Med 2009;36:161-4.

23. Stubbs B, Vancampfort D, Firth J, Schuch FB, Hallgren M, Smith L, et al. Relationship between sedentary behavior and depression: a mediation analysis of influential factors across the lifespan among 42,469 people in low- and middle-income countries. J Affect Disord 2018;229:231-8.

24. Silva AFD, Júnior CASA, Hinnig PF, Lima LRA, Silva DAS. Suicidal behaviors and sedentary lifestyles among adolescents: a cross-sectional epidemiological study in Latin American and Caribbean countries. Clinics (Sao Paulo) 2020;75:e2015. 